\title{
APLICABILIDAD DE UN ACUERDO DE ELECCIÓN DE FORO A UNA RECLAMACIÓN DE INDEMNIZACIÓN DE DAÑOS POR VULNERACIÓN DEL ARTÍCULO 102 TFUE: EL CASO APPLE SALES INTERNATIONAL (C-595/17)
}

\author{
APPLICABILITY OF A JURISDICTION AGREEMENT TO A \\ CLAIM OF DAMAGES BY INFRINGEMENT OF ARTICLE 102 \\ TFEU: THE APPLE SALES INTERNATIONAL CASE (C-595/17)
}

\author{
Alfonso-Luis Calvo Caravaca \\ Catedrático de Derecho Internacional Privado \\ Universidad Carlos III de Madrid \\ Vocal Permanente de la Comisión General de Codificación \\ ORCID ID: 0000-0003-2236-4641 \\ JuLia SUdEROW \\ Profesora de la Universidad de Deusto \\ Abogada
}

Recibido: 24.06.2019 / Aceptado: 18.07.2019

DOI: https://doi.org/10.20318/cdt.2019.4970

Resumen: La aplicación privada del derecho de la Competencia no se limita tan sólo a acciones de daños por infracciones del art. 101 TFUE, sino que también abarca las acciones follow on y stand alone contra los abusos de posición de dominio sancionados por el art. 102 TFUE. Se trata de acciones que tienen su origen en conductas unilaterales en las que las cláusulas de atribución de competencia juegan un papel esencial. El TJUE resuelve con la sentencia Ap-ple Sales ciertas dudas sobre el alcance de estas cláusulas si bien su respuesta genera nuevas cuestiones que podrán plantearse en futuros litigios. La voluntad de las partes y la proporcio-nalidad tendrán que seguir siendo los elementos sobre los que pivote la exclusividad del foro de sumisión expresa.

Palabras clave: acciones para la indemnización de daños anticompetitivos, acciones autónomas, acciones de seguimiento, acuerdos de elección de foro, arbitraje, competencia judicial internacional, Daños, Derecho antitrust, Derecho europeo de la competencia, Unión Europea.

Abstract: Private enforcement of Competition Law is not limited to cartel damage claims based on infringements of art. 101 TFUE. Follow on and Stand alone actions against the abuse of dominance sanctioned by art. 102 TFUE are also included. They are actions derived from unilateral conducts where jurisdiction agreements play an important role. In the ruling Apple Sales, the ECJ solves certain doubts about the scope of this type of clauses but its answer generates new questions that will be dealt in future disputes. The will of the parties as well as the proportionality will still be the basis of the exclusivity of the forum.

Keywords: antitrust damages actions, stand-alone actions, follow-on actions, jurisdiction agreements, arbitration, jurisdiction, damages (Torts), Antitrust Law, European Competition Law, European Union. 
Sumario: I. Planteamiento del problema. II. Origen del problema. III. Doctrina del TJUE. 1. Distanciamiento del caso CDC. A) Diferencia procesal entre ilícitos concurrenciales unilaterales y plurilaterales. B) Calificación del acuerdo de elección de foro como abuso de posición dominante. 2. Hipotética extensión a los acuerdos de arbitraje. 3. Aplicabilidad de la solución a las acciones stand-alone y follow-on. 4. Previsibilidad. A) Doctrina del TJUE. B) Aplicación a nivel nacional. C) Cláusulas de compliance y de daños liquidativos. IV. Conclusión.

\section{Planteamiento del problema}

1. En la actualidad, el Derecho antitrust europeo se apoya, cada vez más, en la denominada "aplicación privada" (private enforcement) del Derecho de la competencia; es decir, en procedimientos civiles ante tribunales civiles de los Estados miembros, cuyo objeto principal suele ser la declaración de nulidad de un contrato contrario a las normas sobre libre competencia ${ }^{1}$ o la indemnización de los daños causados por la infracción de tales normas (arts. 101 y 102 TFUE) ${ }^{2}$. Es -como ha apuntado P. MANKows$\mathrm{KI}-$ una tarea en la que la propia UE junto con contadas excepciones como el Reino Unido, Alemania y Holanda, ha sido pionera ante la pasividad de la mayoría de los Estados miembros y en la que no se debe menospreciar la importancia de las normas de competencia judicial internacional, debido a la frecuencia con la que los acuerdos colusorios o los abusos de posición dominante tienen una dimensión transfronteriza ${ }^{3}$. En efecto, desde sus orígenes las acciones follow on basadas en los hechos constatados en las resoluciones sancionadoras de la Comisión Europea han servido de base a las principales acciones planteadas hasta la fecha. Las propias normas de atribución de competencia sancionadora en favor de la Comisión Europea implican que este organismo sancione conductas que afectan mercado entre dos o más Estados miembros y que las empresas sancionadas pueden estar domiciliadas en distintos Estados miembros. De esta forma, el origen de las reclamaciones, la conducta anticoncurrencial tiene alcance transnacional. Por ello, la competencia judicial internacional juega un rol determinante para la acción follow on basada en la decisión sancionadora de la Comisión Europea. Así, incluso tras la incorporación

\footnotetext{
${ }^{1}$ Vid., ad ex., R. Bechtold, "Umfang und Grenzen der kartellrechtlichen Nichtigkeitssanktionen", en Global wisdom on business transactions, international law and dispute resolution: Festschrift für Gerhard Wegen zum 65. Geburtstag, 2015, pp. 365-375; I. BENÖHR, "The impact of competition law on the private law concepts of nullity and damages", en H.-W./C.H. SIEBURGH (Eds.), Primary EU law and private law concepts, Cambridge, Intersentia, 2017, pp. 133-164; A.-L. Calvo Caravaca, "Derecho antitrust europeo y sanciones civiles: la nulidad (art. 101.2 TFUE)", en L. Prats Albentosa/G. Tomás Martínez (Coord.), Culpa y responsabilidad, Cizur Menor, Thomson Reuters Aranzadi, 2017, pp. 149-172; C. CAUfFMAN, "The impact of Article 101(2) TFEU nullity on private law", en H.-W./C.H. SiebURGH (Eds.), Primary EU law and private law concepts, Cambridge, Intersentia, 2017, pp. 165-205; T. EILMANSBERGER, "Zur Nichtigkeit kartellrechtswidriger Vereinbarungen und ihren Konsequenzen (1. Teil)”, $J B l$, 131, 6, 2009, pp. 337-350; ID., "Zur Nichtigkeit kartellrechtswidriger Vereinbarungen und ihren Konsequenzen (2. Teil)”, JBl, 131, 7, 2009, pp. 427-436; R. FeDERICO, "Operazione economica e nullità dei contratti derivati da intesa anticoncorrenziale", Il corriere giuridico, XXXV, 8-9, 2018, pp. 1066-1074; S. GonZÁlez García, La nulidad de los negocios restrictivos de la competencia, Madrid, Marcial Pons, 2016; C. Herrero SuÁrez, "La nulidad de las conductas anticompetitivas", en La lucha contra las restricciones de la competencia: sanciones y remedios en el ordenamiento español, Granada, Comares, 2017, pp. 223-268; D. HolZINGER, Marktmissbrauch und Nichtigkeit: Vertragsnichtigkeit bei Verstößen gegen das Marktmissbrauchsverbot, Wien, 2012; H. KöHLER, "Wettbewerbsverstoß und Vertragsnichtigkeit", JZ, 65, 15/16, 2010, pp. 767-774; L. MARITZEN, "EuGH, teilweise Nichtigerklärung innerhalb einer einheitlichen und fortdauernden Zuwiderhandlung: EuGH 6.12.2012, Rs C-441/11 P, Coppens", ÖZK, n 2, 2013, pp. 68-72; J. MoHR, "Privatrechtliche Nichtigkeit von Kartellen und öffentlich-rechtlicher Vertrauensschutz", ZWeR, 9 , 4, 2011, pp. 383-406; E. RitTenauer/M.-T. Richter, “Zur Reichweite der kartellrechtlichen Nichtigkeitssanktion: trennbar oder untrennbar, das ist hier die Frage", Ecolex, 26, 10, 2015, pp. 877-881; W.-H. Rотн, "Nichtigkeit von Gesellschaftsverträgen bei Verstoß gegen das europäische Kartellverbot", en Festschrift für Klaus J. Hopt zum 70. Geburtstag am 24. August 2010: Unternehmen, Markt und Verantwortung, vol. 2, Berlin, 2010, pp. 2881-2900; J. ToLD, "Schadenersatz nach § 37a KartG im Verhältnis zu bereicherungsrechtlichen Rückabwicklungsansprüchen aufgrund Nichtigkeit von Kartellfolgeverträgen”, $J B l, 136,1,2014$, pp. 14-27; K. SснміDт, “Kartellnichtigkeit von Folgeverträgen: alles neu seit 'Courage' und seit der Siebenten GWB-Novelle?”, en S. Bechtold/J. Jickeli/M. Rohe (Hrsg.), Recht, Ordnung und Wettbewerb: Festschrift zum 70. Geburtstag von Wernhard Möschel, Baden-Baden, 2011, pp. 559-578; ID., "Nichtigkeit oder Abwicklung kartellrechtswidriger Gemeinschaftsunternehmen? Theorie für die Praxis und sieben Thesen", $B B, 69,10,2014$, pp. 515-520.

${ }^{2}$ Vid., ad ex., R. INDERST/S. ThOMAs, Schadensersatz bei Kartellverstößen: Juristische und ökonomische Grundlagen und Methoden, $2^{\mathrm{a}}$ ed., Düsseldorf, Handelsblatt Fachmedien GmbH, 2018.

${ }^{3}$ P. MANKOWSKI, "Reichweite von Gerichtsstandsvereinbarungen - kartellrechtliche Schadensersatzklage", Juristenzeitung, 2019, pp.141-144 (p. 141).
} 
de la Directiva 2014/104/UE del Parlamento Europeo y del Consejo, de 26 de noviembre de 2014, relativa a determinadas normas por las que se rigen las acciones por daños en virtud del Derecho nacional, por infracciones del Derecho de la competencia de los Estados miembros y de la Unión Europea siguen existiendo diferencias determinantes ${ }^{4}$ entre las distintas jurisdicciones relacionadas con cuestiones procesales, económicas y técnicas entre otros. Por ello, la competencia judicial internacional, sigue siendo una cuestión esencial que en ocasiones puede marcar la viabilidad de la reclamación.

2. Cabe preguntarse si un distribuidor autorizado puede demandar a su proveedor ante los tribunales de un Estado miembro de la UE en virtud de un acuerdo de elección de foro, cuando concurren tres circunstancias: a) se acusa al fabricante o proveedor de haber abusado de su posición dominante en el mercado (art. 102 TFUE) y, por tanto, se le reclama una indemnización por daños causado por dicho abuso; b) el acuerdo de elección de foro que sirve de fundamento a la demanda no se refería explícitamente a que pudiera ser usado ante el tribunal elegido en el caso de acciones judiciales que tuvieran su origen en infracciones del Derecho de la UE en materia de libre competencia; c) no existe ninguna resolución administrativa previa e irrecurrible de ninguna autoridad nacional de competencia de un Estado miembro de la UE ni tampoco de la Comisión Europea que haya declarado que el proveedor hubiese cometido abuso de posición dominante (art. 102 TFUE) (acción stand alone).

3. La STJUE 24 octubre 2018, C-595/17, Apple Sales Internationaly otros, ECLI:EU:C:2018:854, ha dado respuesta a la anterior cuestión ${ }^{5}$. Es una resolución judicial muy importante por varios motivos. En primer lugar, aporta una cierta claridad a un tema delicado y complejo, como es la aplicabilidad de los acuerdos de elección de foro a las infracciones del Derecho europeo de la competencia; ya que colma una laguna de la jurisprudencia europea, tratada hasta la fecha tan sólo por los tribunales nacionales, del Reino Unido, Portugal y Alemania entre otros: si la solución prevista para determinar el alcance de los acuerdos de elección de foro frente a las acciones civiles contra daños causados por acuerdos colusorios (art. 101 TFUE) es la misma en caso de que se trate de acciones civiles contra daños causados por abusos de posición dominante (art. 102 TFUE). En segundo lugar, da pie para que la doctrina plantee si la solución del TJUE al caso Apple Sales International es extrapolable a los acuerdos de arbitraje (Schiedsgerichtsvereinbarungen). No obstante, la conclusión del TJUE invita a pensar que las acciones derivadas de una infracción del art. 101 TFUE, es decir cárteles y otras conductas relacionadas podrán considerarse per se extracontractuales mientras que las acciones derivadas de una infracción del artículo 102 TFUE se clasificarán como obligaciones contractuales a los efectos del Reglamento Bruselas I Bis. Esta conclusión, aparentemente sencilla y de fácil implementación puede generar cierta confusión en la práctica por los motivos que expondremos a continuación. En efecto, una consecuencia natural al aumento de las acciones de daños y a su dimensión transnacional y a su complejidad práctica es el aumento de las cláusulas de atribución de competencia, las cláusulas de cumplimiento de las normas del derecho de la competencia,

\footnotetext{
${ }^{4}$ Sobre la transposición de la Directiva véase, per omnia, C. Herrero SuAREz, "La transposición de la Directiva de daños antitrust. Reflexiones a raíz de la publicación de la propuesta de Ley de transposición de la Directiva", $C D T, 8,1,2016$, pp. 150-183.

${ }^{5}$ Comentada por P.-J. Bueso Guillén, "Cláusulas de sumisión a fuero y ejercicio de acciones de daños y perjuicios derivados de ilícitos 'antitrust'. A propósito del As. C-595/17 Apple vs. MJA”, en J.I. Ruiz Peris (Dir.)/T. Palomar Tejedor (COORD.), Problemas actuales en las acciones de compensación de daños por infracción de las normas de competencia, Cizur Menor (Navarra), Thomson Reuters Aranzadi, 2019, pp. 55-76; P. CARO DE SousA, "Should Jurisdictional Clauses be Interpreted Differently in Competition Law Cases?: A Comment on Case C 595/17 Apple ECLI:EU:C:2018:854”, Competition Policy International, November 2018, pp. 1-6; C. KRÜGER/M. SEegers, "Gerichtsstands- und Schiedsklauseln bei Schadensersatz in Missbrauchs- und Kartellfällen im Lichte des Apple-Urteils des EuGH", WuW, 4, 2019, pp. 170-173; P. MANKowsKi, "Reichweite von Gerichtsstandsvereinbarungen - kartellrechtliche Schadensersatzklage”, Juristenzeitung, 2019, pp.141-144; R.M. Moura RAMOs, “Acórdão de 24/10/2018 (Pactos atributivos de jurisdição e direito da concorrência)", Revista de legislação e de jurisprudência, 2018, pp. 108-131; P. PARADELA ArEÁN, "La eficacia de las cláusulas jurisdiccionales en la aplicación privada del Derecho de la competencia: Sentencia del Tribunal de Justicia de 24 de octubre de 2019, asunto C-595/17: Apple Sales International y otros", La Ley Unión Europea, n 67, 28 febrero 2019; O. SEGGEwISSE, "Anwendbarkeit einer Gerichtsstandsklausel auf Schadensersatzklage wegen Wettbewerbsverstoß", EuZW, 30, 2, 2019, pp. 81-82; D. WIEGANDT, "Zur Anwendung einer Gerichtsstandsklausel auf Schadensersatzklage eines Händlers gegen Lieferanten wegen Marktmachtmissbrauchs ("Apple Sales International u. a.')", EWiR, 2, 2019, pp. 61-62.
} 
así como las cláusulas de determinación de daños liquidativos. Precisamente esto explica la irrupción de estos acuerdos que se refieren a cualquier tipo de infracción del Derecho de la competencia; esto es, tanto al abuso de posición dominante como conductas multilaterales, como puede ser un cártel. Así, la práctica invita a pensar que el análisis deberá plantearse, caso por caso, para poder determinar la voluntad real de las partes en relación al negocio jurídico afectado por la conducta anticompetitiva.

\section{Origen del problema}

4. En 2002, la sociedad irlandesa Apple Sales International y eBizcuss concluyeron un contrato por el que esta última empresa adquiría la condición de revendedor autorizado de productos de la marca Apple. En el contrato, se insertó un acuerdo de elección de foro en virtud del cual se designaba competentes a los tribunales de Irlanda: "This Agreement and the corresponding relationship between the parties shall be governed by and construed in accordance with the laws of the Republic of Ireland and the parties shall submit to the jurisdiction of the courts of the Republic of Ireland. Apple [Sales International] reserves the right to institute proceedings against Reseller in the courts having jurisdiction in the place where Reseller has its seat or in any jurisdiction where a harm to Apple [Sales International] is occurring"6.

5. Pese a dicha cláusula, en 2012, eBizcuss el vendedor autorizado demandó a Apple Sales International y a otras sociedades del grupo Apple (la sociedad estadounidense Apple Inc. y la sociedad francesa Apple Retail France EURL) ante el Tribunal de commerce de París. La demanda ante el tribunal francés se basaba, desde el punto de vista de la competencia judicial internacional, en que Francia era el lugar de los hechos dañosos, y, desde el punto de vista del fondo, en que tales hechos estaban tipificados, como antijurídicos, en el art. 102 TFUE (abuso de posición dominante), además de otras disposiciones legales. Apple Sales International impugnó la competencia del tribunal francés ante el que eBizcuss interpuso la demanda y éste proclamó efectivamente que carecía de competencia judicial internacional para pronunciarse sobre el fondo del asunto, habida cuenta de la existencia de una cláusula de sumisión expresa a los tribunales irlandeses (sentencia Tribunal de commerce de París 26 septiembre 2013). El asunto objeto de discusión, como consecuencia de varias incidencias procedimentales, pasó sucesivamente por un carrusel de diversos tribunales franceses: La Cour d'appel de París, que conoció del recurso interpuesto por eBizcuss contra la anterior resolución judicial y que desestimó dicho recurso (sentencia Cour d'appel de París 8 abril 2014). La Cour de cassation estimó que el tribunal de apelación había infringido la interpretación que el Tribunal de Justicia había dado al art. 23 del Reglamento (CE) n ${ }^{\circ} 44 / 2001$ del Consejo, de 22 diciembre 2000, relativo a la competencia judicial, el reconocimiento y la ejecución de resoluciones judiciales en materia civil y mercantil en el caso CDC Hydrogen Peroxide (sentencia Cour de cassation 7 octubre 2015). Aparentemente así era: el Tribunal de commerce de París había admitido el acuerdo de elección de foro; aunque éste no tenía relación alguna con litigios derivados del incumplimiento del Derecho de la competencia. La Cour de cassation reenvió el caso a la Cour d'appel de Versailles que, a su vez, no tuvo otro remedio que estimar la interpretación dada al art. 23 del Reglamento 44/2001 y lo remitió al tribunal de instancia (el Tribunal de commerce de París) (sentencia Cour d'appel de Versailles 25 octubre 2016). Contra esta última sentencia, las tres sociedades del grupo Apple interpusieron un recurso de casación. Además, el órgano judicial remitente expuso que le constaba que la sentencia del Supremo Tribunal de Justiça de Portugal 16 febrero 2016, Interlog y Taboada c. Apple, había estimado la incompetencia de los tribunales portugueses en un caso de indemnización de daños por abuso de posición dominante, en el que la empresa demandada era también Apple y en el que existía una cláusula atributiva de competencia judicial, redactada en términos generales, semejante a la del caso Apple Sales International (Acórdão do Supremo Tribunal de Justiça de Portugal, nº 135/12.7TCFUN.L1.S1)7.

\footnotetext{
${ }^{6}$ Este acuerdo y la correspondiente relación entre las partes se regirá y se basa en las leyes de la República de Irlanda y las partes se someten a la jurisdicción de los tribunales de la República de Irlanda. Apple [Sales International] se reserva el derecho de iniciar un procedimiento contra el Revendedor ante los tribunales que tengan jurisdicción en el domicilio del Revendedor o en cualquier jurisdicción en la que esté generando un daño a Apple [Sales International].

${ }^{7}$ Disponible en: http://www.dgsi.pt/jstj.nsf/-/1C7619DD818936D680257F5B00541003.
} 
6. La Cour de cassation, probablemente cautiva del síndrome del día de la marmota, suspendió el procedimiento y elevó al Tribunal de Justicia de la UE tres cuestiones prejudiciales:

“1) ¿Debe interpretarse el artículo 23 del Reglamento $n^{\circ} 44 / 2001$ en el sentido de que permite al juez nacional que conoce de una acción por daños y perjuicios ejercitada por un distribuidor contra su proveedor sobre la base del artículo 102 [TFUE] aplicar una cláusula atributiva de competencia prevista en el contrato celebrado entre las partes?

2) En caso de respuesta afirmativa a la primera cuestión, ¿debe interpretarse el artículo 23 del Reglamento $n^{\circ} 44 / 2001$ en el sentido de que permite al juez nacional que conoce de una acción por daños y perjuicios ejercitada por un distribuidor contra su proveedor sobre la base del artículo 102 [TFUE] aplicar una cláusula atributiva de competencia contenida en el contrato celebrado entre las partes, incluso cuando dicha cláusula no contiene una referencia expresa a los litigios relativos a la responsabilidad derivada de una infracción del Derecho de la competencia?

3) ¿Debe interpretarse el artículo 23 del Reglamento $n^{\circ} 44 / 2001$ en el sentido de que permite al juez nacional que conoce de una acción por daños y perjuicios ejercitada por un distribuidor contra su proveedor sobre la base del artículo 102 [TFUE] excluir una cláusula atributiva de competencia prevista en el contrato celebrado entre las partes cuando ninguna autoridad nacional o europea haya detectado una infracción del Derecho de la competencia?" 8.

\section{Doctrina del TJUE}

7. Los acuerdos atributivos de competencia en Derecho antitrust han sido considerados tradicionalmente con recelo y, en todo caso, con meticulosidad (A.-L. Calvo Caravaca/J. Carrascosa GonZÁLEZ) ${ }^{9}$. Estos acuerdos, sin embargo, son objeto de frecuentes discusiones ante los tribunales por varios motivos. Primero, porque el acuerdo de elección de foro prevalece sobre el foro general del domicilio del demandado y sobre los demás foros especiales (como el foro del lugar del hecho dañoso o el del litisconsorcio pasivo) en virtud del principio de jerarquia de las competencias (A.-L. CALVo Caravaca/J. Carrascosa GonzÁlez) ${ }^{10}$. Segundo, porque son de gran interés para los cartelistas, ya que les permiten el cálculo y la reducción del riesgo en el tribunal, si son lo suficientemente amplios y efectivos (P. Mankowski) ${ }^{11}$. Tercero, porque, a diferencia de los foros especiales, los acuerdos atributivos de competencia impiden que los demandantes puedan acudir al forum shopping (P. MANKOWSKI) ${ }^{12}$. Cuarto, permiten acumular las posibles acciones en un solo foro y permiten activar el art. 6 III b del Reglamento Roma II, es decir la aplicación de un solo derecho, el del foro cuando el mercado del foro coincida con el domicilio del demandado y se haya visto afectado directa y sustancialmente por la conducta.

Así, como veremos y a pesar del origen eminentemente extracontractual de estas obligaciones, a medida que la aplicación privada avanza, se consolida su uso en todo tipo de contratos y el reconocimiento de este tipo de acuerdos por parte de los tribunales nacionales ${ }^{13}$.

\footnotetext{
${ }^{8}$ STJUE 24 octubre 2018, C-595/17, Apple Sales International y otros, ECLI:EU:C:2018:854, § 19.

9 Vid., ad ex., A.-L. Calvo Caravaca/J. Carrascosa GonzÁlez, "El Derecho Internacional Privado de la Unión Europea frente a las acciones por daños anticompetitivos", $C D T$, vol. 10, nº 2, Octubre 2018, pp. 7-178 (pp. 42-66).

10 Vid., ad ex., A.-L. Calvo Caravaca/J. Carrascosa González, "El Derecho Internacional Privado de la Unión Europea frente a las acciones por daños anticompetitivos", $C D T$, vol. 10, nº 2, Octubre 2018, pp. 7-178 (pp. 38-39).

${ }^{11}$ P. Mankowski, "Reichweite von Gerichtsstandsvereinbarungen - kartellrechtliche Schadensersatzklage", Juristenzeitung, 2019, pp.141-144 (p. 141).

12 P. MANKOwsKi, "Reichweite von Gerichtsstandsvereinbarungen - kartellrechtliche Schadensersatzklage", Juristenzeitung, 2019, pp.141-144 (p. 141).

${ }^{13}$ Cfr. al respecto, ad ex., el siguiente Auto del Tribunal Supremo Alemán: Beschluss BGH 11 diciembre 2018-KZR 66/17, ECLI:DE:BGH:2018:111218BKZR66.17.0. Vid. J. WÄschLE, Die Internationale Zuständigkeit für Schadensersatzklagen gegen Weltkartelle, Koordination der Gerichtspflichtigkeit in Europa und den USA, Tübingen, Mohr Siebeck, 2017.
} 


\section{Distanciamiento del caso CDC}

8. Según el TJUE debe interpretarse el art. 23 R. 44/2001 en el sentido de que no se debe excluir la aplicación de un acuerdo de elección de foro contenido en un contrato entre las partes a una demanda por daños de un comerciante contra su proveedor que se base en el art. 102 TFUE por el solo motivo de que no se mencionen expresamente en ella los litigios relacionados con la responsabilidad por incumplimiento del Derecho de la competencia ${ }^{14}$.

Esta afirmación entraña, al menos, dos consecuencias procedimentales. Primera, la supuesta víctima del daño anticompetitivo únicamente puede demandar ante el tribunal elegido por las partes, tal como consta en el contrato que se encuentra en la base del litigio. Segunda, el acuerdo de sumisión priva, de ordinario, a la víctima de la posibilidad de interponer su acción ante cualesquiera de los otros foros que hubieran sido competentes, en caso de que el acuerdo de elección de foro no existiera o fuera ineficaz.

9. Desde un punto de vista técnico, el acuerdo atributivo de competencia objeto del litigio era un "acuerdo de sumisión en favor de una parte"; puesto que resultaba más beneficioso para Apple, que era el proveedor, que para eBizcuss, que era el distribuidor. Tales cláusulas, denominadas también "cláusulas asimétricas de sumisión", son frecuentes en contratos bancarios y financieros ${ }^{15}$. Si eBizcuss no impugnó, desde un principio, su validez -al menos, no consta que lo hiciera-, se debe probablemente a que era aplicable el art. 23 R. 44/2002. En la actualidad, este tipo de cláusulas es contrario al art. 25 R. 1215/2012 de 12 diciembre 2012 (Reglamento Bruselas I-bis) ${ }^{16}$.

\section{A) Diferencia procesal entre ilícitos concurrenciales unilaterales y plurilaterales}

10. En el caso que nos ocupa, el Tribunal de Justicia marcó distancias con la jurisprudencia del caso CDC Hydrogen Peroxide. Recuérdese que la STJUE 21 mayo 2015, C-352/13, CDC Hydrogen Peroxide, ECLI:EU:C:2015:335, §§61 y 62, subrayó que: “[...] se debe considerar que el tribunal que conoce del asunto puede estar vinculado en principio por una cláusula atributiva de competencia que excluya las competencias previstas en los artículos 5 y 6 del Reglamento $n^{\circ} 44 / 2001$, estipulada por las partes [...] La exigencia de aplicación eficaz de la prohibición de los cárteles no puede desvirtuar esa conclusión. En efecto, el Tribunal de Justicia ya ha juzgado que las reglas de Derecho material aplicables al fondo de un litigio no pueden tener incidencia en la validez de una cláusula atributiva de competencia que se ajuste al artículo 17 del Convenio mencionado en el apartado 59 de esta sentencia (véase en ese sentido la sentencia Castelletti, C-159/97, EU:C:1999:142, apartado 51). Según la jurisprudencia recordada en el apartado 60 de esta sentencia, esa interpretación también es pertinente para el artículo 23 del Reglamento $n^{\circ} 44 / 2001^{\prime 17}$. Es decir, en este precedente, el TJUE había interpretado

${ }^{14}$ STJUE 24 octubre 2018, C-595/17, Apple Sales International y otros, ECLI:EU:C:2018:854, 30.

${ }^{15}$ Sobre estas cláusulas, vid., ad ex., A.-L. Calvo Caravaca/J. Carrascosa González/C. Caamiña Domínguez, Litigación internacional en la Unión Europea I. Competencia judicial y validez de resoluciones en materia civil y mercantil en la Unión Europea. Comentario al Reglamento Bruselas I Bis, Cizur Menor, Thomson Reuters Aranzadi, 2017, p. 250 (por A.-L. CALvo Caravaca/J. Carrascosa GonzÁlez); L. Merrett, "The future enforcement of asymmetric jurisdiction agreements", ICLQ, 67 , 1, 2018, pp. 37-61.

16 A.-L. Calvo Caravaca/J. Carrascosa González/C. CaAmiña Domínguez, Litigación internacional en la Unión Europea I. Competencia judicial y validez de resoluciones en materia civil y mercantil en la Unión Europea. Comentario al Reglamento Bruselas I Bis, Cizur Menor, Thomson Reuters Aranzadi, 2017, p. 250 (por A.-L. Calvo Caravaca/J. Carrascosa González).

${ }^{17}$ Comentada por N. Boyle/G. ChHoKar/S. Gartagani, "Jurisdiction in follow-on damages claims: update on the judgment of the European Court of Justice in the hydrogen peroxide cartel claim", G.C.L.R., 8, 3, 2015, pp. R58-R62; L. GeELHAND/S. Gartagani, "CDC v Akzo Nobel and Others: Clarifications on the Jurisdiction Rules in Cartel Damages Claims", J.E.C.L. \& Pract., 6, 10, 2015, pp. 713-715; O. Geiss/H. Daniel, "Cartel Damage Claims (CDC) Hydrogen Peroxide SA v Akzo Nobel NV and Others: A summary and critique of the judgment of the European Court of Justice of May, 21 2015", Eur.Compet.L.Rev., 2015 pp. 430-435; C. Harler/J. Weinzierl, "The ECJ's CDC-Judgment on Jurisdiction in Cartel Damages Cases: Repercussions for International Arbitration", EWS, 2015, 3, pp. 121-123; R. HARMS/J.A. SANNER/J. SCHMIDT, "EuGVVO: Gerichtsstand bei Kartellschadensersatzklagen", EuZW, 2015, pp. 584-592; F. KAINER/J. PersCH, "Die CDC-Entscheidung des OLG Düsseldorf: Kollektiver Rechtsschutz und europarechtliches Effektivitätsprinzip”, WuW, 2016, pp. 2-7; G. MäscH, "Blondes Have More Fun (Or Have They?)”, WuW, 2016, pp. 285-291; K.L. Mehrbrey/S. JAEGER, "EuGH-Entscheidung klärt internationale Zuständigkeit von nationalen Zivilgerichten in Kartellschadensersatzfällen”, European Law Reporter, 2015, pp. 146-154; G. 
que, conforme al art. 23 R. 44/2001, había que aplicar un acuerdo de elección de foro a una demanda en virtud del art. 101 TFUE en el supuesto de que dicho acuerdo incluyese expresamente los litigios por infracción del Derecho antitrust ${ }^{18}$. En la hipótesis de que la cláusula de determinación del juez competente no mencionase expresamente los litigios concurrenciales civiles derivados de los supuestos a los que se refiere el art. 101 TFUE, dicha cláusula no sería vinculante (= las pretensiones de indemnización por daños derivados de un cártel no están comprendidas en los acuerdos de elección de foro generales [Kar tellschadensersatzansprüche nicht von allgemeinen Gerichtsstandsvereinbarungen erfasst] ${ }^{19}$.

11. En Apple Sales International, el Tribunal de Justicia interpretó que sólo es aplicable una cláusula de jurisdicción a una acción por daños basada en el art. 102 TFUE, cuando la conducta en cuestión está relacionada con la relación contractual bajo la cual se estableció la cláusula ${ }^{20}$. Si bien los acuerdos de cártel en virtud del artículo 101 del TFUE, en principio, no tienen relación directa con la relación contractual entre un participante del cartel y un tercero, el abuso de una posición dominante en virtud del artículo 102 del TFUE puede manifestarse en las relaciones contractuales ${ }^{21}$. Si ese es el

MuSGER, "Internationale Zuständigkeit für Kartellschadenersatz: EuGH 21.5.2015, C-352/13, CDC Hydrogen Peroxide SA vs Akzo Nobel NV ua, CDC Hydrogen Peroxide: Anmerkung”, ÖB1, 64, 5, 2015, pp. 235-237; M. NegRI, "Una pronuncia a tutto campo sui criteri di allocazione della competenza giurisdizionale nel private antitrust enforcement transfrontaliero: il caso esemplare delle azioni risarcitorie c.d. follow-on rispetto a decisioni sanzionatorie di cartelli pan-europei", Int'l Lis, 2015, pp. 78-84; C. NourisSat, "Action indemnitaire en droit de la concurrence: quand la Cour de justice instaure un nouveau forum actoris au bénéfice des victimes...", Procédures, 2015, no 7, pp. 19-20; A. PAто, "Sentencia del Tribunal de Justicia (Sala 4a) de 21 de mayo de 2015, asunto C-352/13, Cartel Damage Claims (CDC) Hydrogen Peroxide SA c. Akzo Nobel NV y otros", REDI, 2015, pp. 195-198; ID., "Collective Redress for Cartel Damage Claims in The European Union after CDC v Akzo Nobel NV and Others", Yearbook of Private International Law, 2017, pp. 491-506; R. PIKE/Y. Tosheva, "CDC v Evonik Degussa (C352/13) and its potential implications for private enforcement of European competition law", G.C.L.R., 8, 2, 2015, pp. 82-85; C. Reydellet, "Leçon 2: De la matière délictuelle et de sa qualification...", Revue Lamy droit des affaires, 2016, n 111, pp. 33-36; C. ReydelLet, "Leçon 3: De la clause attributive de juridiction et de son sort...", Revue Lamy droit des affaires, 2016, $\mathrm{n}^{\circ}$ 111, pp. 37-39; ; A. STADLER, "Schadensersatzklagen im Kartellrecht - Forum shopping welcome! - Zugleich Besprechung von EuGH, Urteil v. 21.5.2015 - C-352/13”, JZ, 2015, pp. 1138-1149; J. SuDERow, “Acciones derivadas de ilícitos antitrust: El foro especial de la obligación extracontractual después de la sentencia CDC Hydrogen Peroxide", CDT, 8, 2, 2016, pp. 306329; T. Thiede/G. KLUMPE, "A Christmas Carol - strongly inspired by Charles Dickens and CDC Hydrogen Peroxide", NZKart, 2017, p. 643; C. THоLE, “Erfassen Schiedsvereinbarungen auch Kartellschadensersatzansprüche?”, ZWeR, 2017, pp. 133-145; A. TORBJÖRn, “Zuständigkeit und Zuständigkeitskonzentration bei Verstößen gegen europäisches Kartellrecht”, Ecolex, 2015, pp. 968-969; M. WelLeR, "EuGVVO - Zuständigkeitskonzentration bei Schadensersatzklage gegen mehrere Kartellanten und Reichweite einer abweichenden Gerichtsstandsvereinbarung”, RIW, 2015, 9, pp. 603-605; D. WIEGANDt, "EuGVVO: Auskunfts-/Schadensersatzklage gegen mehrere Kartellbeteiligte aus verschiedenen Mitgliedstaaten (Private Enforcement), Rücknahme gegen im Forumsstaat ansässigen Beklagten, Wirkung von Gerichtsstandsklauseln gegenüber Dritten?, 'CDC': EuGH (4. Kammer), Urteil vom 21.5.2015, Rs. C-352/13: EWS-Kommentar”, EWS, 26, 3, 2015, pp. 157-159; T. Woodgate/C. OWEN, "Jurisdiction revisited. Forum shopping in cross-border damages claims", Competition Law Insight, 14, 7, 2015, pp. 16-17; W. WURMNEST, "International jurisdiction in competition damages cases under the Brussels I Regulation: CDC Hydrogen Peroxide", C.M.L.Rev., 2016, pp. 225-247.

${ }^{18}$ STJUE 24 octubre 2018, C-595/17, Apple Sales International y otros, ECLI:EU:C:2018:854, § 25: “Habida cuenta de estas consideraciones, el Tribunal de Justicia ha declarado que el artículo 23, apartado 1, del Reglamento n.o 44/2001, en el caso de que se reclame judicialmente una indemnización a causa de una infracción del artículo 101 TFUE y del artículo 53 del Acuerdo sobre el Espacio Económico Europeo, de 2 de mayo de 1992 (DO 1994, L 1, p. 3), permite tener en cuenta las cláusulas atributivas de competencia contenidas en los contratos de suministro, siempre que esas cláusulas se refieran a las controversias sobre la responsabilidad incurrida a consecuencia de una infracción del Derecho de la competencia (sentencia de 21 de mayo de 2015, CDC Hydrogen Peroxide, C-352/13, EU:C:2015:335, apartado 72)".

19 A. Petrasincu/P. Westerhoff, "Die Anwendbarkeit und Reichweite von Schiedsvereinbarungen in Kartellschadensersatzprozessen: zugleich Besprechung der Entscheidung des LG Dortmund vom 13.09.2017, 8 O 30/16 (Kart)”, WuW, 67, 12, 2017, pp. 585-591 (p. 587).

${ }^{20}$ STJUE 24 octubre 2018, C-595/17, Apple Sales International y otros, ECLI:EU:C:2018:854, §§ 26 y 27: “A la luz de esta jurisprudencia, procede examinar si esta interpretación del artículo 23 del Reglamento n.o 44/2001 y la fundamentación que la sostiene sirven igualmente respecto de una cláusula atributiva de competencia invocada en relación con una controversia relativa a la responsabilidad delictual en la que una de las partes contratantes supuestamente ha incurrido al infringir el artículo 102 TFUE. 27 Tal es el caso cuando el comportamiento anticompetitivo alegado resulta ajeno a la relación contractual en cuyo marco se pactó la cláusula atributiva de competencia".

${ }^{21}$ STJUE 24 octubre 2018, C-595/17, Apple Sales International y otros, ECLI:EU:C:2018:854, § 28: "Pues bien, mientras que el comportamiento anticompetitivo al que se refiere el artículo 101 TFUE, el de las prácticas colusorias, no está, en principio, directamente ligado a la relación contractual entre un participante en dicha práctica y un tercero, sobre el cual la práctica 
caso, la consideración de una cláusula de jurisdicción no sería sorprendente ${ }^{22}$. No sería contrario a su aplicación, por tanto, el hecho de que la cláusula atributiva de competencia judicial internacional no se refiriese expresamente a las controversias que surjan de infracciones del Derecho de la competencia ${ }^{23}$.

\section{B) Calificación del acuerdo de elección de foro como abuso de posición dominante}

12. Tal y como resaltan C. KrÜger/M. SeEgers, la sentencia Apple Sales no se pronuncia respecto a un posible abuso de posición de dominio a través del acuerdo de elección del foro. En efecto, el acuerdo podría considerarse nulo al imponer condiciones abusivas al revendedor. El Tribunal Supremo alemán ha analizado este tipo de acuerdos en casos de sumisión a arbitraje, concluyendo que su validez dependerá del análisis del derecho de acceso a la justicia por parte de la parte contraria y de las condiciones del arbitraje en cada caso $^{24}$.

13. En este sentido, el Tribunal Supremo Alemán analiza la obligación objeto de la reclamación para determinar si puede considerarse contractual o extracontractual a los efectos de fijar el foro. En el caso analizado por el BGH, un hotel alemán había iniciado una acción de declaración de nulidad y daños y perjuicios por un abuso de posición de dominio de Booking.com, la plataforma de reserva de habitaciones que imponía en sus condiciones generales de contratación la sumisión de cualquier disputa a los tribunales holandeses. El demandante también consideraba otras cláusulas abusivas que habían sido impuestas por Booking tras el inicio de la relación contractual. El BGH ha considerado que en este caso la imposición de nuevas condiciones no se puede considerar una conducta derivada del contrato en sí, sino que el motivo de la demanda es la declaración de nulidad de las nuevas condiciones al considerarse la imposición de las mismas un abuso de posición de dominio como tal. Por ello, la disputa gira en torno al abuso de posición de dominio y la imposición de condiciones excesivas y no al contrato como tal. Así el BGH ha concluido que se debe considerar una acción extracontractual por lo que el foro se puede determinar conforme al art. 7.2 R. 1215/2012, excluyendo el foro impuesto por la plataforma de reservas en sus condiciones generales de contratación. Si la obligación se deriva del contrato se podrá considerar contractual, pero si por el contrario se deriva de un posible abuso de una de las partes imponiendo determinadas condiciones, las cuestiones de derecho de la Competencia relativas a la conducta abusiva prevalecen sobre la posible interpretación del contrato.

Las cláusulas de atribución de competencia a un tribunal concreto deben valorarse de otra forma; ya que, en este caso, se intercambia un foro por otro y cualquier foro dentro del espacio judicial europeo es igual de válido. Sin perjuicio de esto, la imposición de un foro que limitase de forma excesiva las posibilidades de acceso a la justicia podría ser valorado de otra forma. Sirva como ejemplo la imposición de un foro completamente ajeno a la relación entre las partes o un foro en el que las costas del procedimiento pudiesen resultar desproporcionadas para la contraparte más débil.

colusoria despliega sus efectos, el comportamiento anticompetitivo al que se refiere el artículo 102 TFUE, a saber, el abuso de posición dominante, puede materializarse en las relaciones contractuales que entabla una empresa en posición dominante y por medio de cláusulas contractuales".

${ }^{22}$ STJUE 24 octubre 2018, C-595/17, Apple Sales International y otros, ECLI:EU:C:2018:854, § 29: “Debe señalarse, por tanto, que, en el marco de una acción fundada en el artículo 102 TFUE, la toma en consideración de una cláusula atributiva de competencia que hace referencia a un contrato y a la relación correspondiente o a las relaciones derivadas del mismo entre las partes no puede considerarse sorprendente para una de las partes en el sentido de la jurisprudencia a la que se refiere el apartado 22 de la presente sentencia".

${ }^{23}$ STJUE 24 octubre 2018, C-595/17, Apple Sales International y otros, ECLI:EU:C:2018:854, § 30: “A la luz de cuanto precede, procede responder a las cuestiones primera y segunda que el artículo 23 del Reglamento n.o 44/2001 debe interpretarse en el sentido de que no cabe excluir la aplicación, respecto a una acción por daños y perjuicios ejercitada por un distribuidor contra su proveedor sobre la base del artículo 102 TFUE, de una cláusula atributiva de competencia contenida en el contrato celebrado entre las partes por la sola razón de que esta cláusula no haga referencia expresa a los litigios relativos a la responsabilidad derivada de una infracción del Derecho de la competencia".

${ }^{24}$ C. KRÜGER/M. SeEgERs, "Gerichtsstands- und Schiedsklauseln bei Schadensersatz in Missbrauchs- und Kartellfällen im Lichte des Apple-Urteils des EuGH”, WuW, 4, 2019, pp. 170-173 (p. 172). Cfr. Sentencia Bundesgerichtshof 7 junio 2016 , ECLI:DE:BGH:2016:070616UKZR6.15.0. 


\section{Hipotética extensión a los acuerdos de arbitraje}

14. En $C D C$ Hydrogen Peroxide, el Tribunal de Justicia dejó sin resolver explícitamente si la solución que había dado a los acuerdos de elección de foro frente a las acciones por daños antitrust era extrapolable, mutatis mutandis, a los acuerdos de arbitraje, cuando tienen por objeto resolver una diferencia entre las partes, cuyo origen se encuentra en un acuerdo colusorio (art. 101 TFUE). Es ésta una cuestión extraordinariamente polémica. Lo es hasta el punto de que, hoy por hoy, la jurisprudencia de los tribunales de Estados miembros de la UE favorable a la extrapolación de soluciones es, por ahora, mínima.

15. Los tribunales de diversos Estados miembros de la UE se han opuesto a que los acuerdos de arbitraje generales (standard arbitration agreements) abarquen las follow-on cartel damage actions ${ }^{25}$. En efecto, dicho con otras palabras, son favorables a la extensión de la solución prevista para los acuerdos de elección de foro que tengan por objeto pretensiones derivadas del art. 101 TFUE a los acuerdos de arbitraje, ad ex.:

a) La sentencia del Gerechtshof de Amsterdam 21 julio 2015, cártel del clorato de sodio ( $\mathrm{Na}$ triumchloraatkartel), ECLI:NL:GHAMS:2015:3006, en que se ejercía una acción colectiva de indemnización (Collectieve actie tot schadevergoeding) y en la que se proclamó que: "No cabe apelar a las cláusulas acordadas de elección de foro y arbitraje. De acuerdo con su redacción, las cláusulas no se refieren a disputas relacionadas con la responsabilidad por infracción del Derecho de la competencia, sino que se refieren, en general (como cláusulas 'abstractas') a disputas que surjan en las relaciones contractuales. Por lo tanto, no se puede considerar que las empresas lesionadas hayan aceptado una elección de foro o arbitraje con el fin de resolver reclamaciones de indemnización por los daños que hayan sufrido como resultado de la participación del proveedor en el cartel ilegal"26.

b) La sentencia del Rechtbank Rotterdam 25 mayo 2016, caso DGL enerzijds contra Kone, Thyssenkrupp, Otis y Mitsubishi, ECLI:NL:RBROT:2016:4164, según la cual: "La cláusula de arbitraje, en este caso, no debe invocarse en el contexto de una reclamación por una infracción de la prohibición del artículo 101 del TFUE por parte de los cárteles; porque no existe ninguna disputa en la relación legal contractual"'27.

16. Por el contrario, la sentencia LG Dortmund 13 septiembre 2017, 8 O 30/16 [Kart] resolvió que los acuerdos de elección de foro generales (los denominados standard arbitration agreements) abarcan las follow-on cartel damage actions ${ }^{28}$. En efecto, el LG Dortmund se declaró incompetente para conocer de una reclamación de daños en el caso del cártel alemán ferroviario (acción follow-on en virtud del art. 101 TFUE); puesto que existía una cláusula compromisoria en el contrato entre el proveedor/infractor y el comprador que invocaba su condición de víctima. Para el LG, no era necesario que la cláusula compromisoria incluyese expresamente los daños derivados del incumplimiento del Derecho

\footnotetext{
${ }^{25}$ A. Petrasincu/P. Westerhoff, "Die Anwendbarkeit und Reichweite von Schiedsvereinbarungen in Kartellschadensersatzprozessen: zugleich Besprechung der Entscheidung des LG Dortmund vom 13.09.2017, 8 O 30/16 (Kart)", Wirtschaft und Wettbewerb, 67, 12, 2017, pp. 585-591 (p. 591).

${ }^{26}$ La traducción es nuestra. El texto original dice así: Beroep op overeengekomen forumkeuze- en arbitragebedingen faalt. De bedingen hebben blijkens hun formulering geen betrekking op geschillen betreffende aansprakelijkheid wegens een inbreuk op het mededingingsrecht, maar verwijzen in het algemeen ('abstract') naar geschillen die in contractuele betrekkingen ontstaan. De benadeelde ondernemingen kunnen dus niet worden geacht te hebben ingestemd met een forum- of arbitragekeuze voor de beslechting van de vorderingen tot vergoeding van de schade die zij hebben geleden door de deelneming van de leverancier aan de onrechtmatige mededingingsregeling).

${ }^{27}$ La traducción es nuestra. El texto original es éste: “Arbitragebeding in dit geval niet in te roepen in het kader van een vordering wegens een inbreuk op het kartelverbod van artikel 101 WVEU omdat geen sprake is van een geschil dat in de contractuele rechtsbetrekking ontstaat".

${ }^{28}$ Disponible en https://openjur.de/u/2156096.html (consultado el 2 mayo 2019) y comentada por A. Petrasincu/P. WesTERHOFF, "Die Anwendbarkeit und Reichweite von Schiedsvereinbarungen in Kartellschadensersatzprozessen: zugleich Besprechung der Entscheidung des LG Dortmund vom 13.09.2017, 8 O 30/16 (Kart)", WuW, 67, 12, 2017, pp. 585-591 (p. 591).
} 
de la competencia y sí que eran suficientes el respeto a la autonomía de la voluntad de las partes y la interpretación más favorable a la cláusula compromisoria (la denominada schiedsfreundliche Auslegung) habitualmente seguida por el $\mathrm{BGH}^{29}$.

17. En este escenario, existen diversas "interpretaciones" en torno a la aplicabilidad de los acuerdos arbitrales a las reclamaciones basadas en presuntas infracciones del art. 102 TFUE, bien ilustradas por acreditada doctrina ${ }^{30}$.

18. Sólo en caso de que efectivamente se aclarase que la solución apuntada por el TJUE en CDC Hydrogen Peroxide para los acuerdos atributivos de competencia judicial internacional es la que mejor refleja el Derecho vigente, cabría plantearse si el caso Apple Sales International constituye un ejemplo de desarrollo jurisprudencial del Derecho Internacional Privado. Hasta que esto no ocurra, la extensión de la doctrina del caso CDC Hydrogen Peroxide a los arbitrajes es, cuando menos, dudosa (zweifelhaft $)^{31}$.

\section{Aplicabilidad de la solución a las acciones stand-alone y follow-on}

19. Según el TJUE el art. 23 R. 44/2001, debe interpretarse en el sentido de que la aplicación de un acuerdo de elección de foro, en el marco de una demanda de indemnización de daños de un comerciante contra su proveedor en virtud del art. 102 TFUE, no está subordinada a la constatación previa de una violación del Derecho de la competencia por una autoridad nacional o europea ${ }^{32}$. Ergo el art. 23 R. 44/2001 es aplicable a las acciones civiles por daños antitrust, tanto si se trata de acciones follow-on como de acciones stand-alone. La solución dada por el TJUE a esta cuestión era la que cabía esperar: "apenas sorprende", como ha señalado D. WIEGANDT ${ }^{33}$. La ratio decidendi no es otra que el hecho de que el Public Enforcement y el Private Enforcement del Derecho antitrust transcurran de manera jurídicamente independiente el uno del otro (Unabhängigkeit) ${ }^{34}$.

${ }^{29}$ Vid., per omnia, C. Steinle/S. Wilske/M. EcKardt, "Kartellschadensersatz und Schiedsklauseln - Luxemburg Locuta, Causa Finita?", zugleich Besprechung des Urteils des EuGH vom 21. Mai 2015 - C-352/13”, Zeitschrift für Schiedsverfahren, 2015, pp. 165-169 (p. 168).

${ }^{30} \mathrm{Vid}$., ad ex., J. BASEDow, "Jurisdiction and Choice of Law in the Private Enforcement of EC Competition Law", en J. Basedow (Hrsg.), Private Enforcement of EC Competition Law, Alphen aan den Rijn, Kluwer Law International, 2007, pp. 229-253 (p. 233); C. Harler/J. WeinzierL, “The ECJ's CDC-Judgment on Jurisdiction in Cartel Damages Cases: Repercussions for International Arbitration", EWS, 2015, 3, pp. 121-123 (pp. 122-123); R. HaRms/J.A. SANNER/J. Schmidt, "EuGVVO: Gerichtsstand bei Kartellschadensersatzklagen", EuZW, 2015, pp. 584-592 (p. 592); R. NAzZINI, “Are claims for tortious damages for breach of the antitrust rules arbitrable in the European Union? Some reflections on the $C D C$ case in the Court of Justice", Rivista Italiana di Antitrust, no 1, 2016, pp. $70-86$ (pp. 79-80); A. Petrasincu/P. Westerhoff, "Die Anwendbarkeit und Reichweite von Schiedsvereinbarungen in Kartellschadensersatzprozessen: zugleich Besprechung der Entscheidung des LG Dortmund vom 13.09.2017, 8 O 30/16 (Kart)", WuW, 67, 12, 2017, pp. 585-591 (p. 585); C. Thole, "Erfassen Schiedsvereinbarungen auch Kartellschadensersatzansprüche?", ZWeR, 15, 2, 2017, pp. 133-145 (pp. 142-143); G. WAGNER, "Schiedsgerichtsbarkeit in Kartellsachen", ZVglRWiss., 114, 4, 2015, pp. $494-515$ (p. 508); D. WIEGANDT, Bindungswirkung kartellbehördlicher Entscheidungen im Zivilprozess, Tübingen, Mohr Siebeck, 2018, p. 112.

${ }^{31}$ D. WIEGANDT, "Zur Anwendung einer Gerichtsstandsklausel auf Schadensersatzklage eines Händlers gegen Lieferanten wegen Marktmachtmissbrauchs ('Apple Sales International u. a.')”, EWiR, 2, 2019, pp. 61-62 (p. 62, no 3.2).

${ }^{32}$ STJUE 24 octubre 2018, C-595/17, Apple Sales International y otros, ECLI:EU:C:2018:854, §§ 32-36.

${ }_{33}$ D. WiEgANDT, "Zur Anwendung einer Gerichtsstandsklausel auf Schadensersatzklage eines Händlers gegen Lieferanten wegen Marktmachtmissbrauchs ('Apple Sales International u. a.')”, EWiR, 2, 2019, pp. 61-62 (p. 62, no 3.3).

${ }^{34}$ D. Wiegandt, "Zur Anwendung einer Gerichtsstandsklausel auf Schadensersatzklage eines Händlers gegen Lieferanten wegen Marktmachtmissbrauchs ('Apple Sales International u. a.')”, EWiR, 2, 2019, pp. 61-62 (p. 62, no 3.3). Sobre la relación de independencia entre ambos procedimientos, vid., ad ex., C. AleXANDER, Schadensersatz und Abschöpfung im Lauterkeits- und Kartellrecht: privatrechtliche Sanktionsinstrumente zum Schutz individueller und überindividueller Interessen im Wettbewerb, Tübingen, Mohr Siebeck, 2010, p. 424; A.P. Komninos, "Public and Private Antitrust Enforcement in Europe: Complement? Overlap?", Comp.L.Rev., 3, 2006, pp. 5-26 (pp. 16-17); K. SснміDт, Kartellverfahrensrecht, Kartellverwaltungsrecht, bürgerliches Recht: Kartellrechtspflege nach deutschem Recht gegen Wettbewerbsbeschränkungen, Köln, Berlin, Bonn, München, Heymann, 1977, pp. 115-116; D. WIEGANDT, Bindungswirkung kartellbehördlicher Entscheidungen im Zivilprozess, Tübingen, Mohr Siebeck, 2018, pp. 82-85 y 88. 


\section{De la previbisilidad}

\section{A) Doctrina del TJUE}

20. El Abogado General NILS WAHL recoge, en su opinión, un requisito para determinar si el foro resulta previsible o no que no han sido reconocidos expresamente por TJUE en su sentencia pero que nos sirve de guía interpretativa: Los acuerdos de atribución de competencia generales no tienen por qué estar limitados sólo a disputas contractuales. En efecto, las obligaciones no contractuales pueden entrar dentro del acuerdo de jurisdicción, si la disputa tiene su origen en la relación contractual. No se trata de la previsibilidad del foro acordado, sino de la previsibilidad de una potencial acción de daños y perjuicios derivada de un incumplimiento de la normativa de defensa de la competencia.

La previsibilidad implica que el acuerdo de sumisión se refiera litigios relacionados con una determinada relación jurídica ${ }^{35}$. Recordemos, además, que la sumisión con carácter general sobre toda disputa que pueda surgir entre las partes con independencia de la naturaleza de la relación jurídica y su posible nulidad no es posible ${ }^{36}$. En efecto, cabe preguntarse, en el caso de demandas de compradores directos sobre la base de un contrato que contenga una cláusula de sumisión, si ésta puede abarcar supuestos tales como una reclamación por los perjuicios causados por precios excesivos derivados de un abuso de posición de dominio, ya que el precio será en principio el acordado por las partes ${ }^{37}$.

21. En el caso del abuso de posición de dominio aquí planteado resulta sencillo establecer la "conexión a una relación jurídica concreta" en el sentido exigido por el art. 25 R. 1215/2012 (ex. Art. 23 R. 44/2001). Ahora bien, no podemos olvidar que, en algunos supuestos, la demanda tiene su origen en el abuso de posición de dominio y no en la relación contractual en sí. Para analizar cada caso, el tribunal deberá determinar, en primer lugar, qué ley gobierna el pacto de sumisión y, en un segundo paso, si éste incluye la demanda planteada dentro del mismo. El cumplimiento del Derecho antitrust no es una obligación contractual en sí, sino más bien una obligación legal con independencia de la relación jurídica que una a las partes ${ }^{38}$. Además, habrá que valorar las expectativas de las partes en el momento de celebración del contrato y, por tanto, del pacto de sumisión. Finalmente, habrá que valorar el contrato en su conjunto. Si el contrato contiene, como veremos, cláusulas de compliance por las que las partes se comprometen expresamente a implantar sistemas de prevención de infracciones o imponen la terminación del contrato en caso de sanción por incumplimiento del Derecho de la competencia o, incluso, determinan la fórmula de liquidación del daño causado, una posible disputa resulta previsible, cabrá considerar que la cláusula de sumisión a un determinado foro no tendrá carácter sorpresivo.

\section{B) Aplicación a nivel nacional}

22. En este sentido, merecen una especial atención los litigios surgidos en el Reino Unido contra el cártel de las vitaminas y en concreto el caso Provimi. Parte de los perjudicados plantearon sus acciones resarcitorias ante los tribunales del Reino Unido y Alemania. Las demandadas con domicilio en Europa y en parte en el Reino Unido alegaron que los jueces no podían declararse competentes debido a la existencia de cláusulas de sumisión para cualquier disputa relacionada con los contratos de compraventa de vitaminas ${ }^{39}$.

${ }^{35}$ STJCE, 10 marzo 1992, Duffryn, C 214/89, Rec 1992 p. 1745, apdo. 14.

${ }^{36}$ STJCE, 10 marzo 1992, Duffryn, C 214/89, Rec. 1992, p. 1745, apdo. 14.

${ }^{37}$ D. P. TzaKas, Die Haftung für Kartellrechtsverstösse im internationalen Rechtsverkehr, Baden Baden, Nomos 2011, p. 133. UK, H.C. Bord Na Mona vs. BPI, 2012 EWHC 3346.

38 J. BASEDow, "Jurisdiction and Choice of Law" en J. BASEDow, Private Enforcement of EC Competition, La Haya, Kluwer 2008, p. 229-254; D. P. TzaKas, Die Haftung für Kartellrechtsverstösse im internationalen Rechtsverkehr, Baden Baden, Nomos 2011, p. 133.

${ }^{39}$ F. W. Bulst, "Private Kartellrechtdurchsetzung durch die Marktgegenseite-deutsche Gerichte auf Kollisionskurs zum EuGH, 31/2004" en NJW 2004, p 2201. F. W. BULST, "The Provimi Decision of the High Court: Beginnings of Private Antitrust Litigation in Europe” en EBOR 4 2003, pp. 623-650. 
Debido a la pluralidad de pactos y partes, el juez inglés aplicó las leyes de Suiza, Alemania y Francia para concluir que algunos de los pactos de sumisión, a pesar de su amplia y genérica redacción, no abarcaban acciones de daños y perjuicios por ilícitos antitrust; puesto que éstas se debían a un cártel ilegal más que a la relación contractual que había unido a demandantes y demandados. Los demandantes, en el momento de celebrar el contrato, no conocían ni la existencia de un cártel de fijación de precios ilegal ni que iban a pagar un precio excesivo como consecuencia del propio cártel por los productos objeto del contrato ${ }^{40}$.

Así, durante cierto tiempo, la relación contractual entre Trouw Alemania y Roche Alemania estuvo sujeta a la siguiente cláusula de elección de foro incluida en las condiciones generales de contratación de Roche: "The place of jurisdiction of all disputes arising out the legal relationship between us and the buyer is the Local Court of Lörrach and the District Court of Freiburg".

La High Court consideró que esta cláusula no podía incluir el tipo de litigio planteado por lo que negó la aplicación del acuerdo de sumisión a la acción iniciada en el Reino Unido. Curiosamente, tuvo que emplear los siguientes argumentos para apuntalar su decisión: Los tribunales mencionados en la cláusula no son competentes para asuntos relativos al Derecho de la competencia. La cláusula se refiere a los Amtsgerichte o juzgados de primera instancia más cercanos al domicilio social de Roche Alemania. Los procedimientos civiles en Alemania por demandas inferiores a 5.000 Euros son competencia de los juzgados locales o Amtsgerichte mientras que los Landgerichte o Juzgados provinciales tratan demandas que superen estos importes. Los asuntos antitrust son competencia de los tribunales provinciales designados a tal efecto y ninguno de los tribunales mencionados en la cláusula había sido designado para conocer asuntos antitrust ${ }^{41}$.

Adicionalmente, la High Court concluyó que los tribunales alemanes no acostumbraban a extender el ámbito de cláusulas de elección de foro a acciones delictuales o derivadas de un fraude, basándose en dos sentencias, una del Oberlandesgericht Hamburgo y otra del Oberlandesgericht de Stuttgart, en las que los tribunales concluían que no era intención de las partes incluir demandas basadas en fraude o engaño contractual cuando se referían a "todas las disputas sobre la base de este contrato" 4 . Según la High Court los tribunales alemanes exigen una indicación clara y sin ambigüedades para incluir demandas delictuales dentro del ámbito de aplicación de una cláusula de elección de foro ${ }^{43}$.

Por último, la High Court aplicó la doctrina Powell Duffryn, que establece que la cuestión relevante que debe ser contestada por el tribunal nacional es si la disputa sobre la relación legal es la misma que unía a las partes cuando se tomó el acuerdo de jurisdicción ${ }^{44}$.

23. En el asunto Ryanair, la Court of Appeal rechazó la existencia de una relación estrecha entre el precio cartelizado y la cláusula de sumisión, a pesar de que el contrato incluía una cláusula de adaptación de precios ${ }^{45}$. El tribunal considera que resultaría sorprendente para un "reasonable businessman" incluir una demanda basada en incumplimiento de la normativa antitrust en un contrato de compraventa de combustible; aunque este contrato contenga una cláusula de adaptación de precios y dos procedimientos separados puedan convertirse en una pesadilla probatoria o "forensic nightmare"

\section{C) Cláusulas de cumplimiento y daños liquidativos}

23. Sin perjuicio de anterior, y gracias al fomento de la aplicación privada, la aplicación privada se ha convertido en un elemento habitual en contratos de compraventa de determinada envergadura

${ }^{40}$ C. Ryngaert, Foreign to Foreign Claims in Antitrust Matters: The U.S. Supreme Court's Decision (2004) v. The English High Court's Decisions (2003) in the Vitamins Case, K.U. Leuven, 2006 consultado por última vez el 21.3.2014 en http://www. law.kuleuven.be/iir/nl/onderzoek/wp/WP58e.pdf.

${ }^{41}$ UK H.C. 6 mayo 2003 Provimi 2003 EWHC 961, aptdo. 38.

${ }^{42}$ OLG Hamburg, 12 febrero 1981, en RIW (1982), p. 669 y OLG Stuttgart, 14 Diciembre 1973, BB (1974), p. 1270.

${ }^{43}$ UK H.C., 6 mayo 2003, Provimi 2003 EWHC 961 aptdo. 38.

${ }^{44}$ STJCE, 10 marzo 1992, Duffryn, C 214/89, Rec. 1992, p. 1745. E. GotTSCHALK, S. BressLer, "Missbrauchskontrolle von Gerichtsstandsvereinbarungen im europäischen Zivilprozessrecht“ en ZeuP 2007, pp. 56-80.

${ }^{45}$ UK. C.A., 19 noviembre 2013, Ryanair Esso Italiana Srl, WC2A2LL.

${ }^{46}$ UK. C.A., 19 noviembre 2013, Ryanair Esso Italiana Srl, WC2A2LL. 
y en procedimientos de contratación pública las jurisdicciones más concienciadas. Especial mención merecen los contratos que contienen cláusulas de carácter material relacionadas con el Derecho de la competencia por las que las partes se comprometen a cumplir con el Derecho de la competencia o cláusulas de compliance, así como cláusulas para determinar y liquidar el potencial daño ${ }^{47}$. Una vez más, nos encontramos con una situación en la que las partes regulan su reacción ante posibles incumplimientos del Derecho de la competencia y la liquidación de los efectos de la conducta anticoncurrencial. En este tipo de casos, las partes sí consideran que el incumplimiento puede tener lugar y que la parte perjudicada reclamará el supuesto daño, pudiendo establecer el método de cálculo en el propio acuerdo ${ }^{48}$. Así, estos acuerdos se han considerado perfectamente válidos ante los tribunales alemanes. En este tipo de casos, aunque la conducta ilícita no estaba prevista, sí podía resultar previsible, lo que lleva a las partes a regular un mecanismo de liquidación del posible daño. A efectos de determinación de la competencia judicial internacional en este tipo de reclamaciones, podríamos concluir que el foro que determinen las partes también se referirá a este tipo de acciones. En efecto, ambas partes asumen que existe el riesgo potencial de que el proveedor pueda verse involucrado en una conducta anticompetitiva. Además, ambas partes, incluso, acuerdan cómo calcular el daño y continuar su relación tras la liquidación del mismo. De esta forma, un acuerdo de sumisión que se refiera a cualquier cuestión relacionada con el contrato puede incluir una reclamación de daños, incluso en aquellos casos en los que se trate de un cártel.

\section{Conclusión}

24. La sentencia Apple Sales aporta seguridad jurídica. No obstante, una aplicación cuasi automática, catalogando las acciones derivadas de un abuso de posición de dominio como obligaciones contractuales a los efectos del Derecho Internacional Privado europeo, puede llevar a resultados no previstos por las partes. El abuso de posición de dominio puede ir acompañado de cláusulas abusivas y de acuerdos de sumisión de foro recogidos en condiciones generales de contratación normalmente de la parte con posición de dominio. Por ello, una aplicación automática, en la que no se analice si el acuerdo de elección del foro supone un abuso en sí, puede implicar consecuencias negativas para la parte más débil y perjudicada.

La consideración como contractual, a los efectos de fijar la competencia judicial internacional, puede plantear problemas con la determinación del Derecho aplicable y bloquear el acceso a las posibilidades que brinda el artículo 6.3 b Reglamento Roma II, aplicable a obligaciones extracontractuales.

25. Adicionalmente, cuando las partes contemplen en los contratos posibles conductas ilícitas y regulen sus consecuencias, podríamos asumir que ambas partes han negociado con el suficiente conocimiento y han tenido oportunidad de reaccionar frente a una cláusula que implique una limitación de los foros disponibles, incluso la derivación de la disputa al arbitraje internacional. Así, y siguiendo la línea del TJUE a la hora de valorar los acuerdos de competencia judicial internacional, cada caso merece una valoración detallada de todas las circunstancias, de la cláusula como tal, de la previsibilidad del foro y del contexto del acuerdo desde la perspectiva del Derecho de la competencia.

\footnotetext{
${ }^{47}$ Véase al respecto Roger Halson, Liquidated damages and penalty clauses, Oxford, Oxford University Press, 2018.

${ }^{48}$ K. Sснмidt, "§ 33 GWB und Private Enforcement auf vertraglicher Grundlage", $W u W, 2015$, pp. 812-821; J. SudERow, "Aplicación privada del Derecho de competencia. Comentario a la primera sentencia relativa a una acción follow on contra el cártel de los camiones Sentencia del Tribunal Regional, Landgericht Hannover, de 18 diciembre de 2017, 18 O 8/17, LKW Kartell”, Revista de Derecho de la Competencia y de la Distribución, n. ${ }^{\circ} 22$, enero-junio 2018, 1 de ene. de 2018, pp.1-10.
} 